\title{
Dipolar and Nonpolar Altitudinal Molecular Rotors Mounted on an Au(111) Surface
}

\author{
Xiaolai Zheng, Mary E. Mulcahy, Dominik Horinek, Francesco Galeotti, Thomas F. Magnera, and \\ Josef Michl*
}

Department of Chemistry and Biochemistry, University of Colorado, Boulder, Colorado 80309-0215

Received November 7, 2003; E-mail: michl@eefus.colorado.edu

\section{(W) This paper contains enhanced objects available on the Internet at http://pubs.acs.org/journals/jacsat.}

Traditional interest in thermal and electric field induced molecular rotation in gases, liquids, and inside bulk solids ${ }^{1}$ has recently extended to surface-mounted ${ }^{2-9}$ and unidirectional ${ }^{5,10,11}$ rotors. Our interest in surface-mounted molecular rotors originated in the "Tinkertoy"12 concept ${ }^{13-15}$ of constructing nanosize structures and machinery by covalent binding of molecular rods and connectors. Rotors reported so far were of the azimuthal type (axle normal to the surface). Now, we describe the altitudinal (axle parallel to the surface) molecular rotors 1 (nonpolar) and 2 (dipolar). Such rotors may be ultimately useful, for example, in nanofluidics, electronics, and photonics.

Synthesis of the rotors $\mathbf{1}$ and $\mathbf{2}$ is outlined in Scheme 1 (formulas 1-9). Tolane dimerization ${ }^{16,17}$ with $\mathrm{CpCo}(\mathrm{CO})_{2}$ was extended to cross-dimerization to yield $\mathbf{3 a}$. After some effort, ${ }^{18}$ Kabalka's version ${ }^{19}$ of Suzuki coupling ${ }^{20}$ emerged as the best method for arylto-aryl coupling of sandwich complexes of type $\mathbf{3}$ and, specifically, for the attachment of the rotator $\mathbf{4}$ or $\mathbf{5}$ to the phenyls in $\mathbf{3 b}$ and $\mathbf{3 c}$. Decamercuration was inspired by a prior synthesis of $\mathbf{1 0}$ by pentamercuration. ${ }^{21}$ It is intolerant of triple bonds, which offer lower rotational barriers, but ensures flexibility in the introduction of affinity for a surface, as any thiol will rapidly displace $\mathrm{CF}_{3} \mathrm{CO}_{2}$. The choice of $\mathrm{CH}_{3} \mathrm{~S}\left(\mathrm{CH}_{2}\right)_{2} \mathrm{SH}$ was guided by the strong adhesion ${ }^{21,22}$ of $\mathbf{1 0}$ to the closely analogous $\mathrm{Hg}$ surface.

The benzene planes in the rotator of $\mathbf{2}$ are calculated ${ }^{23}$ to lie at a $16^{\circ}$ twist, left-handed $(\mathrm{M})$ or right-handed $(\mathrm{P})$. From dynamic ${ }^{19} \mathrm{~F}$ NMR, $\Delta G^{\ddagger}(171 \mathrm{~K})=6.3(2) \mathrm{kcal} / \mathrm{mol}$ for $\mathrm{M}-\mathrm{P}$ interconversion in $2,{ }^{24}$ and $\Delta G^{\ddagger}(182 \mathrm{~K})=6.7(3) \mathrm{kcal} / \mathrm{mol}$ in 11 (calculated $^{23} E_{\mathrm{a}}$, $6.2 \mathrm{kcal} / \mathrm{mol}$ ). Barriers to single bond rotations in $\mathbf{1}$ and $\mathbf{2}$ were too low to study by NMR; model calculations ${ }^{23}$ suggest $\sim 3 \mathrm{kcal} / \mathrm{mol}$. In biphenyl, ${ }^{25}$ a barrier $E_{\mathrm{b}} \simeq 1.4 \mathrm{kcal} / \mathrm{mol}$ is overcome as the $o$-hydrogens pass each other, and another, $E_{\mathrm{b}} \simeq 1.6 \mathrm{kcal} / \mathrm{mol}$, as the rings become orthogonal. Clearly, in free $\mathbf{1}$ and $\mathbf{2}$, barriers to rotation around the rotator axle are insignificant at room temperature. The equilibrium orientation of the rotator accommodates the aryls carried by each cyclobutadiene, whose four planes are $\sim 35^{\circ}$ tilted $^{17}$ to form a $\mathrm{P}$ or $\mathrm{M}$ propeller. The stereoisomers of $\mathbf{2}$ are MMM, MMP, MPM, and PPP, PPM, PMP, where the outside letters state the chirality of the tetraarylcyclobutadienes and the inside letter states that of the rotator.

Adsorption from solution was used to prepare monolayers and submonolayers of $\mathbf{1}, \mathbf{2}\left(\mathrm{CH}_{2} \mathrm{Cl}_{2}\right)$, and $\mathbf{1 0}$ (THF) on $\mathrm{Au}(111),{ }^{26}$ monitored by ellipsometry, ${ }^{27}$ a quartz crystal microbalance, ${ }^{28}$ and $\mathrm{X}$-ray photoelectron spectroscopy, ${ }^{29}$ which showed that over days in the open atmosphere, some of the sulfur atoms oxidize, presumably first those attached to mercury. Individual molecules in submonolayers were imaged by $\mathrm{STM}^{30}$ (Supporting Information, Figure S1) and found to be immobile over hours of scanning, both

4540 a J. AM. CHEM. SOC. 2004, 126, 4540-4542
Scheme $1^{a}$
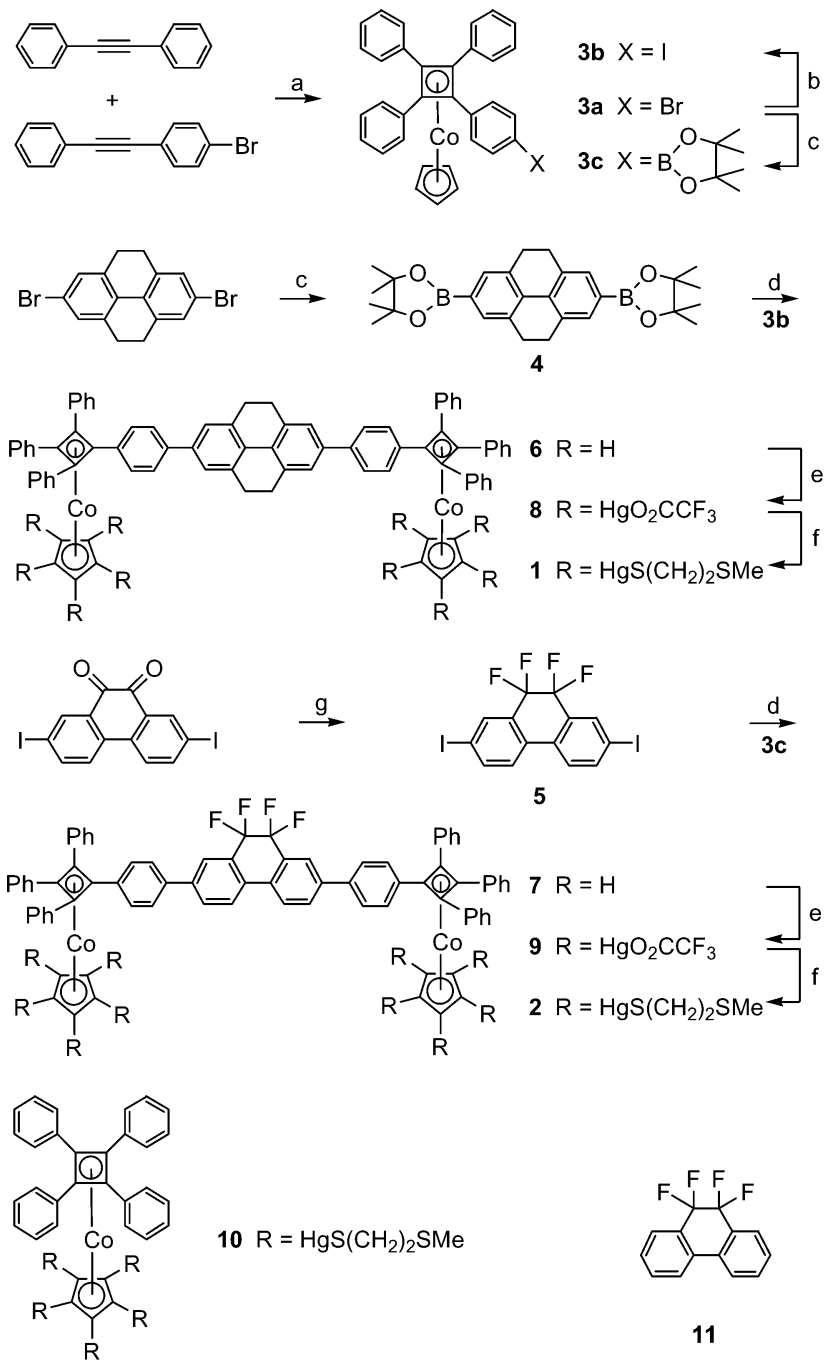

${ }^{a} \mathrm{Key}$ : (a) $\mathrm{CpCo}(\mathrm{CO})_{2}$; (b) $t$ - $\mathrm{BuLi}, \mathrm{I}_{2}$; (c) bis(pinacolato)diboron, $\mathrm{PdCl}_{2}$ (dppf), KOAc; (d) Pd black, KF; (e) $\mathrm{Hg}\left(\mathrm{O}_{2} \mathrm{CCF}_{3}\right)_{2}$; (f) $\mathrm{HS}\left(\mathrm{CH}_{2}\right)_{2} \mathrm{SMe}$; (g) $\mathrm{F}_{3} \mathrm{SNEt}_{2}$.

on fresh and on oxidized months-old samples. Their surface areas varied with imaging conditions and were roughly $2-3 \mathrm{~nm} \times 4-5$ $\mathrm{nm}(\mathbf{1}$ and 2$)$ and $\sim 2.5 \mathrm{~nm} \times \sim 2.5 \mathrm{~nm}(\mathbf{1 0})$, compatible with stretched-tentacle structures on $\mathrm{Au}(111)$ optimized with the molecular dynamics program TINK ${ }^{2,31}$ (Figure 1; in the absence of oxidation, the calculated areas are $\sim 9 \mathrm{~nm}^{2}$ for any diastereomer of $\mathbf{1}$ and $\mathbf{2}$, and $\sim 4 \mathrm{~nm}^{2}$ for 10). For comparison, the footprint of $\mathbf{1}$ and 2 obtained from compression isotherms on an $\mathrm{Hg} / \mathrm{CH}_{3} \mathrm{CN}$ 

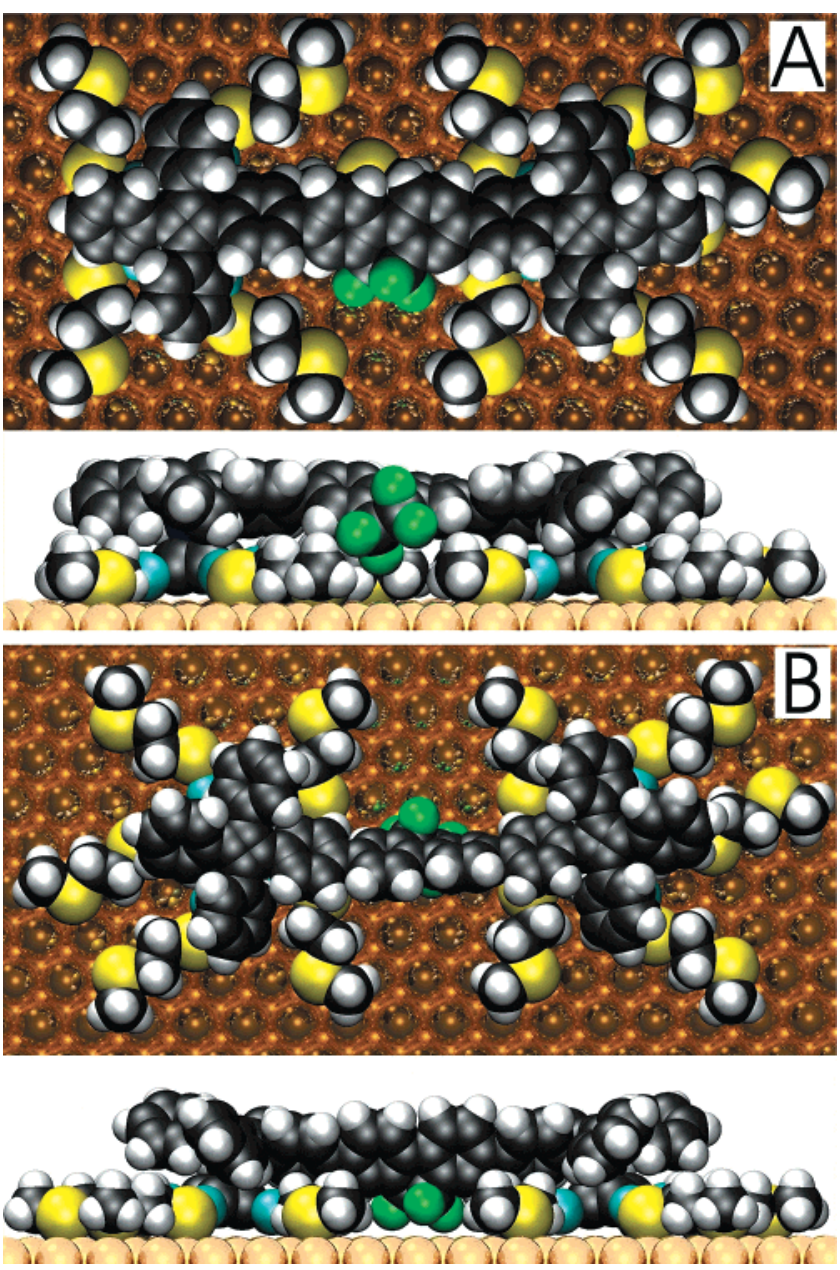

Figure 1. Optimized representative eclipsed (A) and staggered (B) conformations of the MMP diastereomer of 2 on $\mathrm{Au}(111)$.

(10) A movie of panel B in AVI format is available.

interface in an electrochemical Langmuir trough ${ }^{32}$ was $8.5 \mathrm{~nm}^{2}$ (at $-0.8 \mathrm{~V}$ against $\mathrm{Ag} / \mathrm{AgCl}$ ); $4.5 \mathrm{~nm}^{2}$ was found for $\mathbf{1 0}$ (potential independent to $-1.15 \mathrm{~V}$ ).

Can the mounted rotors turn? The two optimized ${ }^{31}$ surfacemounted stretched-tentacle structures shown in Figure 1 represent conformational extremes for the MMP isomer of $\mathbf{2}$ on $\mathrm{Au}(111)$ : A stands for conformations in which the rotator is eclipsed by one or two of the 10 tentacles, and B stands for those in which the rotator is staggered with both sets of tentacles. The drawings are similar for all three diastereomers; MMP is the most stable, MMM is $\sim 3$ $\mathrm{kcal} / \mathrm{mol}$ higher, and MPM is $\sim 6 \mathrm{kcal} / \mathrm{mol}$ higher. In each case, A is $\sim 6 \mathrm{kcal} / \mathrm{mol}$ less stable than B. These small energy differences probably are within the intrinsic uncertainty of the method of calculation, ${ }^{31}$ but the geometries are considered fairly reliable. The computed barrier for MMP $\rightarrow$ MMM isomerization is $\sim 14 \mathrm{kcal} /$ mol. In all diastereomers of $\mathrm{A}$, the tentacles prevent rotation of the rotator and force its dipole direction to form an angle $\alpha \simeq 90^{\circ}$ with the surface normal. In $\mathrm{B}$, the rotator clears the gold surface easily; MMP favors $\alpha \simeq 20^{\circ}$, MMM favors $\alpha \simeq 0^{\circ}$, and the largest $E_{\mathrm{b}}$ in these is $\sim 8 \mathrm{kcal} / \mathrm{mol}$. MPM favors $|\alpha| \simeq 45^{\circ}$, and the maximum $E_{\mathrm{b}}$ is $\sim 3 \mathrm{kcal} / \mathrm{mol}$. Molecular mechanics thus suggests that the room-temperature surface carries a variety of rotor structures: in some, the rotator is locked parallel to the surface, and in others, it flips rapidly between orientations roughly perpendicular to the surface.

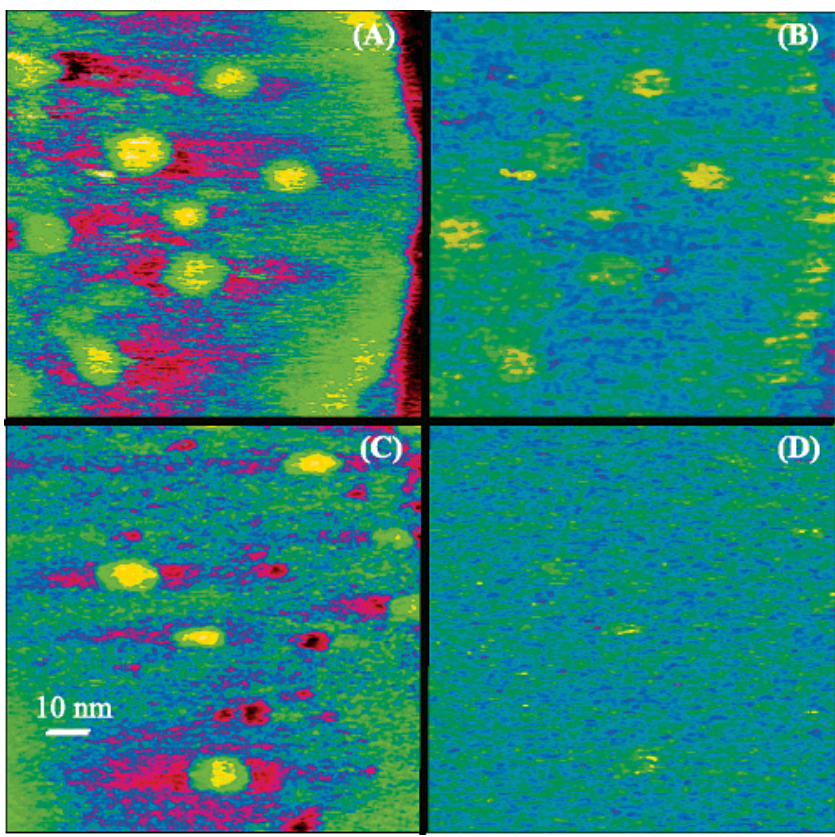

Figure 2. Constant current mode $(200 \mathrm{pA}, 200 \mathrm{mV}) \mathrm{STM}(\mathrm{A}, \mathrm{C})$ and differential BHI (B,D) images of $\mathbf{1}$ (bottom) and $\mathbf{2}$ (top) on $\mathrm{Au}(111)$. Six colors (black, maroon, blue, green, yellow, and white) divide equally the vertical range (left, $0-1 \mathrm{~nm}$; right, $0.0-0.2 \mathrm{~V}$ ). In STM, the molecules appear as bright yellow spots with green rims.

This result is compatible with the pseudo-ATR ${ }^{33}$ IR spectrum of a monolayer of $\mathbf{2}$ on gold, ${ }^{34}$ which demonstrates that $\alpha \neq 0^{\circ}$ for a significant fraction of the rotors. The different degree of attenuation of the intense IR peaks of the rotator, of a $\left[I_{\mathrm{Au}}(\mathrm{a})\right]$ or $\mathrm{b}$ $\left[I_{\mathrm{Au}}(\mathrm{b})\right]$ symmetry, relative to their intensity in a $\mathrm{KBr}$ pellet $\left[I_{\mathrm{iso}}(\mathrm{a})\right.$ or $I_{\text {iso }}(\mathrm{b})$ ], combined with standard selection rules, ${ }^{35}$ yields an approximate average value $|\alpha|=\sim 45^{\circ}{ }^{36}$ The vibrations were identified by comparison of the spectra of $\mathbf{2}, \mathbf{1 0}$, and 11. Their transition moment directions were assumed to be those of $\mathbf{1 1},{ }^{37}$ which were deduced from its linear dichroism in stretched polyethylene. ${ }^{38}$ Angles $\phi$ between the transition moments of b-symmetry vibrations and the rotator axle agreed within $20-30^{\circ}$ with the results of calculations. ${ }^{23}$

If a thermally activated dipole of a rotor indeed flips between orientations pointing roughly toward or away from the surface, an imposed $\sim 10^{9} \mathrm{~V} / \mathrm{m}$ electric field of an STM tip will lock its direction (if the two orientations are intrinsically equally favorable, the field will dictate the dipole direction over $99 \%$ of the time at $25{ }^{\circ} \mathrm{C}$, using the calculated ${ }^{23}$ dipole moment of 11, 3.7 D). The local work function responds sensitively to the presence of a surface dipole $^{39}$ and will be different for the two locked orientations, making them detectable by tunneling barrier height imaging (BHI). ${ }^{40}$ Faint differential $\mathrm{BHI}^{41}$ spots are seen for all rotors $\mathbf{1}$ and on the average about two-thirds of rotors $\mathbf{2}$ on $\mathrm{Au}(111)$, and are assigned to induced molecular dipoles. ${ }^{39}$ The bright spots seen for the remaining rotors 2 are attributed to their flipping permanent dipoles (Figure 2). Repeated scans over a set of molecules show blinking on a time scale of tens of minutes for molecules $\mathbf{2}$ but not $\mathbf{1}$. These results are compatible with the absence and presence, respectively, of a permanent dipole in the rotator of $\mathbf{1}$ and $\mathbf{2}$, and with the availability of conformations of type A (rotator locked) and of type B (rotator free), with any given rotor sharing its time between the two types of conformation. ${ }^{42}$ Additional shades of brightness are presumably provided by conformational differences within type B and by the existence of three diastereomeric forms, which differ in the favored angle $\alpha$. 
It would be interesting to drive the rotator flipping of $\mathbf{2}$ on $\mathrm{Au}(111)$ at microwave frequencies. According to molecular dynamics runs ${ }^{31}$ for $\mathrm{B}$ conformers, an alternating electric field perpendicular to the surface will induce unidirectional rotation in the MMP and, to a smaller degree, MPM isomers and random flipping in the MMM isomer. The directionality is due to the asymmetry of the rotational potential about the direction of the surface normal. ${ }^{43} \mathrm{~A}$ typical run for the MMP form $\left(90 \mathrm{GHz}, 3 \times 10^{9} \mathrm{~V} / \mathrm{m}, 300 \mathrm{~K}\right)$ can be viewed by clicking on Figure $1 \mathrm{~B}$ in the web edition. At low temperatures, $\mathbf{2}$ is calculated to behave as an approximately critically damped single-molecule parametric oscillator. The choice of electric field frequency and amplitude dictates the frequency of the net unidirectional rotation of its rotator, from zero to synchronous with the field, with intermediate subharmonic steps $(1 / 2,1 / 4)$. At room temperature, stereoisomer interconversion will be rapid, and the average behavior of each rotor molecule will be bidirectional.

In summary, we have fabricated and characterized surfacemounted altitudinal rotors $\mathbf{1}$ and $\mathbf{2}$ on gold and have provided evidence that at room temperature the flipping of the rotator in a fraction of rotors $\mathbf{2}$ is subject to a small enough barrier to occur spontaneously and to be controllable by the electric field of an STM tip. In the MMP (and PPM) and, to a small degree, the MPM (and PMP) stereoisomers, unidirectional rotation is predicted in alternating electric field.

Acknowledgment. This paper is dedicated to Prof. Rudolf Zahradník on the occasion of his 75th anniversary. The work was supported by the U.S. Army Research Office (DAAD19-01-1-0521). D.H. thanks the Alexander von Humboldt Foundation for a Feodor Lynen fellowship. The authors are grateful to Profs. C. P. Kubiak and M. Lieberman for stimulating discussions.

Supporting Information Available: Details of synthesis and STM images of $\mathbf{2}$ and $\mathbf{1 0}$ on $\mathrm{Au}(111)$ (PDF). This material is available free of charge via the Internet at http://pubs.acs.org.

\section{References}

(1) Tailored crystals are now being designed: Godinez, C. E.; Zepeda, G.; Garcia-Garibay, M. A. J. Am. Chem. Soc. 2002, 124, 4701.

(2) Vacek, J.; Michl, J. New J. Chem. 1997, 21, 1259.

(3) Gimzewski, J. K.; Joachim, C.; Schlitter, R. R.; Langlais, V.; Tang, H.; Johannsen, I. Science 1998, 281, 531.

(4) Hersam, M. C.; Guisinger, N. P.; Lyding, J. W. Nanotechnology 2000, 11,70 .

(5) Yasuda, R.; Noji, H.; Kinosita, K., Jr.; Yoshida, M. Cell 1998, 93, 1117. Yasuda, R.; Noji, H.; Kinosita, K., Jr.; Itoh, H. Nature 2001, 410, 898.

(6) Vacek, J.; Michl, J. Proc. Natl. Acad. Sci. U.S.A. 2001, 98, 5481.

(7) Clarke, L. I.; Horinek, D.; Kottas, G. S.; Varaska, N.; Magnera, T. F.; Hinderer, T. P.; Horansky, R. D.; Michl, J.; Price, J. C. Nanotechnology 2002, 13, 533 .

(8) Jian, H.; Tour, J. M. J. Org. Chem. 2003, 68, 5091

(9) Horinek, D.; Michl, J. J. Am. Chem. Soc. 2003, 125, 11900.

(10) Kelly, T. R.; Tellitu, I.; Sestelo, J. P. Angew. Chem., Int. Ed. Engl. 1997, 36, 1866. Kelly, T. R.; Silva, R. A.; De Silva, H.; Jasmin, S.; Zhao, Y. J. Am. Chem. Soc. 2000, 122, 6935.

(11) Koumura, N.; Zijlstra, R. W. J.; van Delden, R. A.; Harada, N.; Feringa, B. L. Nature 1999, 401, 152. Koumura, N. L.; Geertsema, E. M.; van Gelder, M. B.; Meetsma, A.; Feringa, B. L. J. Am. Chem. Soc. 2002, 124, 5037. Leigh, D. A.; Wong, J. K. Y.; Dehez, F.; Zerbetto, F. Nature 2003, $424,174$.

(12) Tinkertoy is a trademark of Playskool, Inc., Pawtucket, RI 02862, and designates a toy construction set of wooden sticks insertable into connectors.

(13) Kaszynski, P.; Michl, J. J. Am. Chem. Soc. 1988, 110, 5225.

(14) Michl, J.; Kaszynski, P.; Friedli, A. C.; Murthy, G. S.; Yang, H.-C.; Robinson, R. E.; McMurdie, N. D.; Kim, T. In Strain and Its Implications in Organic Chemistry; de Meijere, A., Blechert, S., Eds.; NATO ASI Series, Vol. 273; Kluwer Academic Publishers: Dordrecht, The Netherlands, 1989; p 463.

(15) Kaszynski, P.; Friedli, A. C.; Michl, J. J. Am. Chem. Soc. 1992, 114, 601.

(16) Rausch, M. D.; Genetti, R. A. J. Org. Chem. 1970, 35, 3888

(17) Harrison, R. M.; Brotin, T.; Noll, B. C.; Michl, J. Organometallics 1997, 16,3401 .
(18) Smith, J.; Jindřich, J.; Častulík, J.; Kottas, G.; Schwab, P.; Trujillo, M.; Rubio, S.; Brotin, T.; Michl, J., unpublished results.

(19) Kabalka, G. W.; Namboodiri, V.; Wang, L. Chem. Commun. 2001, 775.

(20) Miyaura, N.; Suzuki, A. Chem. Rev. 1995, 95, 2457.

(21) Brotin, T.; Pospíšil, L.; Fiedler, J.; King, B. T.; Michl, J. J. Phys. Chem. $B$ 1998, 102, 10062

(22) Pospíšil, L.; Varaksa, N.; Magnera, T. F.; Brotin, T.; Noll, B. C.; Michl, J., unpublished.

(23) BLYP, def-SV(P) basis set, with ECP-60-MWB for Hg, using the RI approximation: Eichkorn, K.; Weigend, F.; Treutler, O.; Ahlrichs, R. Chem. Phys. Lett. 1995, 242, 652. TURBOMOLE program suite, http:// www.turbomole.de.

(24) Below $-80^{\circ} \mathrm{C}$, a weak broad signal appears at somewhat lower $\delta$ values, presumably due to a minor diastereomer. ${ }^{1} \mathrm{H}$ and ${ }^{13} \mathrm{C}$ spectra do not change down to $-110^{\circ} \mathrm{C}$

(25) Almenningen, A.; Bastiansen, O.; Fernholt, L.; Cyvin, B. N.; Cyving, S. J.; Samdal, S. J. Mol. Struct. 1985, 128, 59.

(26) Substrates were either purchased from Molecular Imaging, Inc., or prepared by thermal evaporation of gold at $1 \AA / \mathrm{s}$ on mica that had been heated to $350{ }^{\circ} \mathrm{C}$ at $5 \times 10^{-7}$ Torr for at least $2 \mathrm{~h}$. The film was then heated to 450 ${ }^{\circ} \mathrm{C}$ for $30 \mathrm{~min}$, allowed to cool under vacuum, and annealed with a hydrogen flame immediately before use. STM imaging showed large terraces of $\mathrm{Au}(111)$.

(27) Rudolph Research AutoEL instrument.

(28) QCM100, Stanford Research Systems, simultaneously monitored the frequency and resistance changes of the crystal as the rotors were deposited from a $\sim 10^{-6} \mathrm{M}$ solution onto a $5 \mathrm{MHz}, 1$ " diameter, AT-cut quartz crystal with a polished gold surface.

(29) A Physical Electronics model 5800 XPS spectrometer with a hemispherical analyzer, a resistive multichannel detector, and a monochromatic $\mathrm{Al} \mathrm{K} \alpha$ line $(1486.6 \mathrm{eV}) \mathrm{X}$-ray source was used. Survey scans from 10 to 1000 $\mathrm{eV}$ were acquired with a pass energy of $187.5 \mathrm{eV}$ in steps of $0.8 \mathrm{eV}$. Higher resolution spectra of $\mathrm{Co}, \mathrm{F}, \mathrm{Hg}$, and $\mathrm{S}$ were obtained with a pass energy of $23.5 \mathrm{eV}$ in steps of $0.1 \mathrm{eV}$ and confirmed the presence of the elements expected for each sample. An attempt is underway to determine the abundance of bound and unbound thioether sulfur atoms, the degree of oxidation, and the likely role of $\mathrm{Hg}$ atoms in surface adhesion.

(30) Imaged at room temperature with Nanoscope 3a, Digital Instruments, Inc., under hexadecane unless noted otherwise.

(31) The TINK molecular dynamics program ${ }^{2}$ based largely on the MOIL 6.2 code: Elber, R.; Roitberg, A.; Simmerling, C.; Goldstein, R.; Li, H.; Verkhiver, G.; Keasar, C.; Zhang, J.; Ulitsky, A. Comput. Phys. Commun. 1994, 91, 159, uses the UFF energy function: Rappe, A. K.; Casewit, C. J.; Colwell, K. S.; Goddard, W. A., III; Skiff, W. M. J. Am. Chem. Soc. 1992, 114, 10024. Interaction with the metal surface has been modeled by bonds to selected Au atoms, all of which are fixed, and adding image charges as in: Okuno, Y.; Yokoyama, T.; Yokoyama, S.; Kamikado, T.; Mashiko, S. J. Am. Chem. Soc. 2002, 124, 7218. Electronic friction due to the motion of the image charges within the metal (Tomassone, M. S ; Widom, A. Phys. Rev. B 1997, 56, 4938) has been treated by Langevin dynamics (van Gunsteren, W. F.; Berendsen, H. J. C. Mol. Phys. 1982 45, 637), with an integrator based on: Paterlini, M. G.; Ferguson, D. M. Chem. Phys. 1998, 236, 243.

(32) Varaksa, N.; Pospíšil, L.; Magnera, T. F.; Michl, J. Proc. Natl. Acad. Sci. U.S.A. 2002, 99, 5012

(33) Harrick, N. Internal Reflection Spectroscopy; John Wiley \& Sons: New York, 1967. Mulcahy, M.; Berets, S.; Milosevic, M.; Michl, J. J. Phys. Chem. B 2004, 108, 1519.

(34) Glass microscope slides with $20 \mathrm{~nm}$ of Ti and $200 \mathrm{~nm}$ of Au, deposited by thermal evaporation.

(35) Pearce, H. A.; Sheppard, N. Surf. Sci. 1976, 59, 205.

(36) $\tan ^{2} \alpha=\left[I_{\text {iso }}(\mathrm{a}) / I_{\mathrm{Au}}(\mathrm{a})\right] /\left[\sin ^{2} \phi I_{\text {iso }}(\mathrm{b}) / I_{\mathrm{Au}}(\mathrm{b})\right]$.

(37) Vibrations of a symmetry $\left(v / \mathrm{cm}^{-1}: 1014,1229,1259\right)$, and b symmetry $\left(v / \mathrm{cm}^{-1}, \phi_{\text {exp }} / \mathrm{deg}, \phi_{\text {calcd }} / \mathrm{deg}: 1273,49,24 ; 1150,48,43 ; 1091,44,71\right.$; $1072,66,60 ; 1047,51,82)$

(38) Michl, J.; Thulstrup, E. W. Spectroscopy with Polarized Light. Solute Alignment by Photoselection, in Liquid Crystals, Polymers, and Membranes; VCH Publishers: Deerfield Beach, FL, 1995.

(39) Akiyama, R.; Matsumoto, T.; Kawai, T. Phys. Rev. B 2000, 62, 2034.

(40) Sakai, A. In Advances in Materials Reasearch: Advances in Scanning Probe Microscopy; Sakurai, T., Watanabe, Y., Eds.; Springer-Verlag: New York, 2000; p 143. Hasegawa, Y.; Jia, J. F.; Sakurai, T.; Li, Z. Q.; Ohno, K.; Kawazoe, Y. In Advances in Materials Reasearch: Advances in Scanning Probe Microscopy; Sakurai, T., Watanabe, Y., Eds.; SpringerVerlag: New York, 2000; p 167.

(41) Differential BHI at $5 \mathrm{kHz} 0.2 \AA$ vertical modulation of the tip position with lock-in detection and interleaved scanning with alternating polarity.

(42) At room temperature, thioether sulfur atoms are likely to move from one to another Au atom with fair frequency. Even the much more strongly attached thiols diffuse readily on the Au surface: Barrena, E.; Ocal, C.; Salmeron, M. J. Chem. Phys. 1999, 111, 9797.

(43) For calculated induction of unidirectional rotation of a segment of a chiral molecule by a linearly polarized laser pulse, see: Hoki, K.; Yamaki, M.; Koseki, S.; Fujimura, Y. J. Chem. Phys. 2003, 118, 497; 2003, 119, 12393. In our case, chirality is present but is not required.

JA039482F 